\title{
A rare case of urinary bladder rupture and rupture uterus in an unscarred uterus during vacuum assisted vaginal delivery
}

\author{
Latika*, Pushpa Dahiya, Anjali Gupta, Reetu Hooda, Krishna Dahiya
}

Department of Obstetrics \& Gynecology, PT. B. D. Sharma, PGIMS, Rohtak, Haryana, India

Received: 06 December 2015

Accepted: 08 January 2016

\author{
*Correspondence: \\ Dr. Latika, \\ E-mail: latika.duhan@gmail.com
}

Copyright: (c) the author(s), publisher and licensee Medip Academy. This is an open-access article distributed under the terms of the Creative Commons Attribution Non-Commercial License, which permits unrestricted non-commercial use, distribution, and reproduction in any medium, provided the original work is properly cited.

\begin{abstract}
Operative vaginal delivery is the use of a vacuum or a forceps device to assist the mother in effecting vaginal delivery of a fetus. The incidence of operative vaginal delivery in U.S.A is 5\% or one in 20 deliveries. A 30 year old Para 2 was referred to our institute with complaints of abdominal distension and urinary catheter draining hemorrhagic urine since her delivery. Patient gave history of a Vacuum assisted vaginal delivery three days back at a government hospital. Her previous obstetric history was uneventful. On general examination, she was conscious, with B.P. 110/60 $\mathrm{mm}$ of $\mathrm{Hg}$ and pulse rate was $84 / \mathrm{min}$. Mild pallor was present. Abdominal examination revealed a distended and tender abdomen. Laparotomy was performed along with a team of general surgeon and Urologists. Rupture of uterus in an unscarred uterus is a very rare entity with an estimated occurrence of one in 8000 to 15,000 deliveries 8 . Common risk factors for rupture uterus are caesarean section, inappropriate prostaglandin and oxytocin usage, previous instrumental abortion, instrumental delivery, vigorous fundal delivery, etc. Assisted vaginal delivery using vacuum or forceps avoids unnecessary caesarean sections, and thus reduces the associated morbidity. Different studies have proved vacuum is safer than forceps; however expertise is needed for the application of both the instruments.
\end{abstract}

Keywords: Uterine rupture, Bladder rupture, Vacuum extraction

\section{INTRODUCTION}

Operative vaginal delivery is the use of a vacuum or a forceps device to assist the mother in effecting vaginal delivery of a fetus. The incidence of operative vaginal delivery in U.S.A is $5 \%$ or one in twenty deliveries. ${ }^{1-3}$ Although the rate of operative vaginal delivery is declining these days, still vacuum assisted vaginal deliveries are increasing and it has been estimated that these account for almost four times the forceps assisted deliveries. ${ }^{2,4}$ Though vacuum assisted deliveries are quite safe in experienced hands, incorrect application may lead to dreaded complications like uterine and urinary bladder rupture.

\section{CASE REPORT}

A 30 year old Para 2 was referred to our institute with complaints of abdominal distension and urinary catheter draining hemorrhagic urine since her delivery. Patient gave history of a Vacuum assisted vaginal delivery three days back at a government hospital. Outcome of delivery was a stillborn male baby. She also gave history of application of excessive fundal pressure to expedite the delivery. Immediately after the delivery, she collapsed and resuscitation was done and one unit blood was transfused. Subsequently, she developed abdominal distension. After catheterization of the urinary bladder hemorrhagic urine was noticed. She was then referred to our institute. Her previous obstetric history was uneventful. On general examination, she was conscious, 
with B.P. $110 / 60 \mathrm{~mm}$ of $\mathrm{Hg}$ and pulse rate was $84 / \mathrm{min}$. Mild pallor was present. Abdominal examination revealed a distended and tender abdomen. There was guarding with rebound tenderness and evidence of free fluid was present. Paracentesis was performed, and hemorrhagic fluid drained. On vaginal examination, a Foley's catheter bulb was felt by the examining finger through the cervix and a provisional diagnosis of rupture uterus with urinary bladder rupture was made. Patient's relatives were explained the condition of the patient and an informed consent for laparotomy was taken. Possibility of hysterectomy was also explained to the patient as well as her relatives. Adequate blood was arranged. Laparotomy was performed along with a team of general surgeon and Urologists. Per operatively, around two litres of urine mixed with blood was drained from the abdomen. Uterine rupture in lower uterine segment with extension superiorly to involve the upper uterine segment was found (Figure 1). Uterus was repaired to restore the anatomy and bilateral tubal ligation was performed. According to urologists, there was a large rent (around $8 \mathrm{~cm}$ ) involving the bladder and extending from the trigone of the bladder to its dome. Both ureteric orifices were seen and were normal. Bladder repair was performed with placement of supra pubic catheter. Exploration of the intestines was done by surgeons to rule out any associated injury. Peritoneal lavage was done and abdomen was closed. Post operatively the patient was given broad spectrum intravenous antibiotics. The postoperative period was uneventful and she was discharged after two weeks and thereafter followed up in OPD.

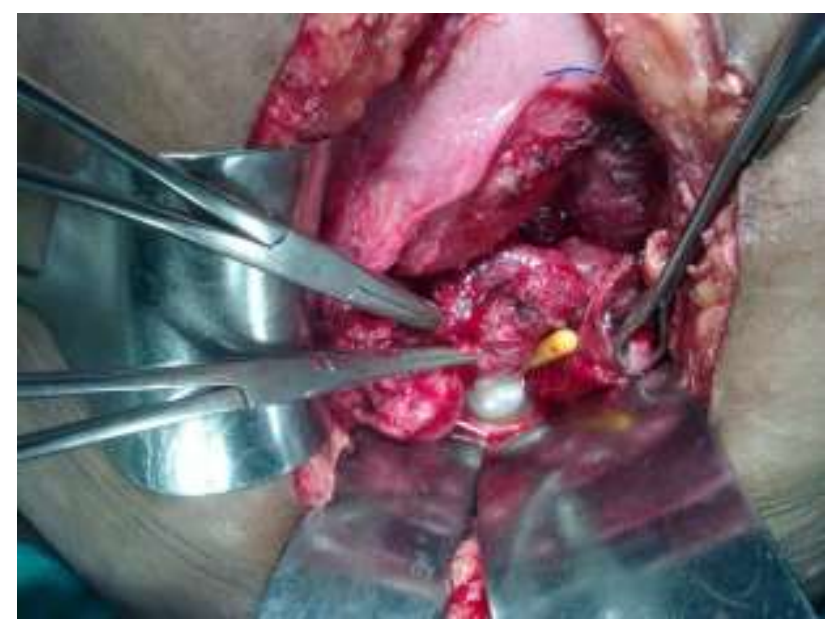

Figure 1: Intraoperative picture showing rupture of the uterus and urinary bladder (Foley's catheter seen).

\section{DISCUSSION}

Application of a forceps or vacuum, to assist a vaginal delivery, has comparable efficacy rates, with comparatively less maternal morbidity than caesarean section. ${ }^{5}$ Despite this fact, cases of operative vaginal delivery are declining. ${ }^{6}$ Complications which can occur during vacuum assisted vaginal delivery can be maternal or fetal or both. Maternal complications commonly encountered are vaginal, cervical or perineal tears. Fetal complications include scalp abrasions, sloughing, cephalhematoma, sub-galeal hemorrhage. Bladder rupture and rupture uterus are very rare complications encountered during vacuum assisted vaginal delivery. Urinary bladder rupture mainly occurs due to incorrect application of vacuum and failure to empty the urinary bladder before vacuum extraction. In the present case, the woman had revealed that at the time of delivery, she had not evacuated her bladder. Other rare conditions in which bladder rupture is seen in association with pregnancy are diverticulum antenatally, during caesarean section, or during trial of labour in a patient with prior caesarean. ${ }^{7}$ Rupture of uterus in an unscarred uterus is a very rare entity with an estimated occurrence of one in 8000 to 15,000 deliveries. ${ }^{8}$ Common risk factors for rupture uterus are caesarean section, inappropriate prostaglandin and oxytocin usage, previous instrumental abortion, instrumental delivery, vigorous fundal delivery etc., These cases are diagnosed in the intrapartum or postpartum period and managed by either total repair of the rent or at times subtotal hysterectomy. In our case, rupture uterus was most probably due to excessive fundal pressure application. Fundal pressure is the application of steady pressure on the fundus of the uterus to expedite delivery and is considered to be one of the most controversial maneuvers performed during second stage of labour. In a review by Guney et al, one out of eight ruptured unscarred uterus cases, was found to be related to the application of fundal pressure. ${ }^{10}$

\section{CONCLUSION}

Assisted vaginal delivery using vacuum or forceps avoids unnecessary caesarean sections, and thus reduces the associated morbidity. Different studies have proved vacuum is safer than forceps; however expertise is needed for the application of both the instruments. Prerequisites for operative delivery and all the Do's and Don'ts should be strictly followed to avoid dreaded complications.

\section{Funding: No funding sources Conflict of interest: None declared Ethical approval: Not required}

\section{REFERENCES}

1. Drife JO. Choice and instrumental delivery. BJOG. 1996;103:608-11.

2. O'Grady JP, Pope CS, Hoffman DE. Forceps delivery. Best Pract Res Clin Obstet Gynaecol. 2002;16:1-16.

3. Kozak LJ, Weeks JD. Trends in obstetric procedures, 1990-2000. Birth. 2002;29:157-61.

4. Bailey PE. The disappearing art of instrumental delivery: time to reverse the trend, Int $\mathrm{J}$ Gynaecol Obstet. 2005;91(1):89-96. 
5. Bofill JA, Rust OA, Schorr SJ. A randomized prospective trial of obstetric forceps versus the $\mathrm{M}$ cup vacuum extractor, AJOG. 1996;175(5):1325-30.

6. Shamshad. Factor leading to increased cesarean section rate, current trend, J Surg Pak. 2007;12(2):64-6.

7. Wandabwa J, Tom TO, Kiondo P. Spontaneous rupture of bladder in puerperium. Afr Health Sci. 2004;4:138-9.

8. Pan HS, Huang LW, Hwang JL, Lee CY, Tsai YL, Cheng WC. Uterine rupture in an unscarred uterus after application of fundal pressure. J Reprod Med. 2002;47:1044-6.
9. Wang PH, Yuan CC, Chao HT, Yang MJ, Ng HT. Posterior uterine wall rupture during labour. Hum Reprod. 2000;15:1198-9.

10. Güney M, Oral B, ñzsoy M, Demir F, ñzbaşar D. Nedbesiz uterus rüptürü: 8 olgunun analizi. Uzmanlik Sonrasi Eğitim ve Güncel Gelismeler Dergisi. 2005;2:342-6.

Cite this article as: Latika, Dahiya $\mathrm{P}$, Gupta A, Hooda R, Dahiya K. A rare case of urinary bladder rupture and rupture uterus in an unscarred uterus during vacuum assisted vaginal delivery. Int J Reprod Contracept Obstet Gynecol 2016;5:559-61. 